\title{
Nurses' Knowledge, Attitudes and Opinions Towards Clinical Research: A Cross-Sectional Study in a University Hospital
}

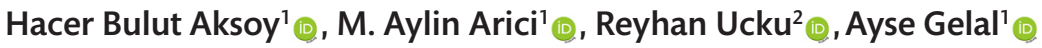 \\ 'Dokuz Eylul University, Pharmacology, İzmir, Turkey \\ ${ }^{2}$ Dokuz Eylul University, Public Health, İmir, Turkey \\ Address for Correspondence: Ayse Gelal, E-mail: ayse.gelal@deu.edu.tr \\ Received: 14.02.2018; Accepted: 05.04.2018; Available Online Date: 30.05 .2018 \\ (OCopyright 2018 by Dokuz Eylül University, Institute of Health Sciences - Available online at www.jbachs.org
}

Cite this article as: Aksoy Bulut H, Arici MA, Ucku R, Gelal A. Nurses' Knowledge, Attitudes and Opinions Towards Clinical Research: A Cross-Sectional Study in a University Hospital. J Basic Clin Health Sci 2018; 2:38-44. https://doi.org/10.30621/jbachs.2018.403

\begin{abstract}
Purpose: To investigate the nurses' knowledge and attitudes toward clinical research, and their opinions about clinical research nursing and the factors affecting them.

Methods: Our study is a cross-sectional study. The data was collected in August 2015 via a questionnaire. 48-item questionnaire was used to assess the knowledge, attitudes, opinion, and to obtain sociodemographic characteristics of the nurses. Each correct/positive answer was marked as 1 point.

Results: Among the 306 nurses selected by stratified random sampling, 291 (95\%) responded to the questionnaires. Only $8.6 \%$ of the nurses were involved in clinical research, and 3.8\% of the nurses had relevant training. The mean knowledge level of nurses regarding clinical research was $10.1 \pm 4.1$ (max: 19) and the average positive attitude score of them was $5.8 \pm 1.7$ (max: 8). There was a positive correlation between the knowledge level and the attitude scores. Nurses who have relevant training, experience, and also patients consulting about clinical research had significantly higher knowledge level than the others. More than $77 \%$ of the nurses had knowledge of the volunteer definition, the informed consent, and the confidentiality of the volunteers. Less than $50 \%$ of the nurses have knowledge about clinical research design, ethical guidelines, clinical trial regulations, and vulnerable population. The nurses who agreed on "the clinical research nursing should be a separate profession" and also shown their willingness to be assigned to clinical researches had relatively higher knowledge and attitude scores.

Conclusion: Both knowledge and attitude scores of the nurses had a significant impact on nurse's opinions corresponding to specialization, education, and participation in clinical research. The results indicate that staff nurses have only limited knowledge about clinical research while they are willing to be trained in this subject.
\end{abstract}

Keywords: Clinical research; clinical research nurse; clinical research nursing, nurses' knowledge; nurses' attitudes; nurses' opinions

\section{INTRODUCTION}

Clinical research is conducted with great care, and in accordance with ethical and legal regulations. It plays an important role in the development of health services and in the quality of patient care (1-4). The availability of new treatment options or the improvement of existing treatments can only be achieved through clinical research.

The success of clinical research depends on the educational levels and competence of clinical research team members and good collaboration among them (5). A Clinical Research Nurse (CRN) is one of the important members of this multidisciplinary research team. The roles and responsibilities of nurses in clinical research may be varied according to the type of clinical research, and the institutions in which the clinical research is conducted as well as the nurses' knowledge, education level, and abilities in the areas that they are interested in $(3,6)$. The International Association of Clinical Research Nurses (IACRN) defines the CRN as a specialized practice of professional nursing focused on maintaining equilibrium between care of the research participant, and fidelity to the research protocol (The International Association of Clinical Research Nurses, n.d.). This means that $C R N$ s have critical roles and responsibilities in assuring volunteers' safety, maintenance of informed consent, ensuring the integrity of protocol implementation, the accuracy of data collection, data recording, and follow-up (7-12). Moreover, 
they have an important role to raise the awareness of clinical research to patients and the public. (13-15).

Increasing the number of qualified clinical researches is one of the strategic objectives of our country. In order to reach this objective many action plans have been implemented, one of which is the training of CRNs. Clinical research nursing is a new concept in Turkey and standard training programmes, framework and legislation in this subject have not yet been put into practice. There are only a limited number of nurses working as CRNs (16). Therefore, more staff nurses need to be involved in clinical research.

The purpose of this study is to investigate the staff nurses knowledge and attitudes towards clinical research and their opinions about clinical research nursing, and the factors affecting them. The study was conducted in a university hospital, which is one of the most important clinical research centers in Turkey. It is also aimed to generate useful outputs which may support future actions to improve the current status of nurses involved in clinical researches in our country. To our knowledge, this is the first study in Turkey which specifically examines the aims outlined above.

\section{METHODS}

This descriptive, cross-sectional study was conducted between 01 August 2015 and 31 August 2015 in Dokuz Eylul University Hospital, İzmir, Turkey. The total population of the study was 751 nurses who work in medical $(n=413)$ and surgical $(n=338)$ departments at Dokuz Eylul University Hospital. For 95\% confidence level, 50\% unknown prevalence, $5 \%$ precision, the sample size was calculated as 255 nurses. Considering a non-response rate of $20 \%, 306$ nurses were selected by stratified random sampling. Only the nurses who volunteered were included in the study. Those who participated in the preliminary study for the questionnaire preparation were excluded.

This study was approved by Dokuz Eylul University Ethics Committee for Non-Interventional Research, and was conducted in accordance with the Declaration of Helsinki. The data was collected via a questionnaire formed by the researchers. During the preparation of the questionnaire, consultation was obtained from specialists, and guidance was obtained from previous studies $(5,17,18)$. The questionnaire used in this study was peer-reviewed, and had been tested in a preliminary study involving 10 nurses. After assessing their results and feedbacks, any unclear or complex questions/items were corrected or removed from the questionnaire upon finalization.

The questionnaire had four sections. The first section contained 14 questions in order to determine the descriptive characteristics of the nurses participating in this research such as age, gender, area of work, educational background, whether or not they had clinical research experience, etc.

The second section had 19 items regarding basic knowledge of clinical research, ethical concepts, regulations, research design, and volunteering concepts. For each statement, there were three possible choices: "true" "false" or "no idea". Each right answer was marked as "1" point, wrong as well as "no idea" answers were marked as " 0 " points for the calculations. The minimum score for one participant was " 0 " and maximum score for one participant was "19" for this section. A higher score represents higher level of knowledge in clinical research.

Section three had 8 items to evaluate the attitude of nurses towards clinical research. In this section, a three-point scale (agree, don't agree, neither agree nor disagree) was used. Each positive answer was marked as "1" point, negative as well as "neither agree nor disagree" answers were marked as "0" points for the calculations. Maximum score for one participant was " 8 " while minimum score for one participant was " 0 " for this section. A higher score is associated with more a positive attitude towards clinical research.

The last section had 5 questions and two items regarding participants' opinions related to clinical research education and clinical research nursing.

\section{Statistical Analysis}

The collected data was recorded using IBM SPSS - 20.0 (IBM SPSS Statistics, 2011; Armonk, NY, USA). Descriptive statistics were made for data analysis. The results were presented as number (n), percentage (\%), mean ( \pm ), and standard deviation (SD). One-way ANOVA was conducted in multiple groups comparisons and $t$-test was used in two independent groups comparisons. Relationship between knowledge level and attitude was evaluated by performing a correlation analysis. The significance level was set at $\mathrm{p}<0.05$.

\section{RESULTS}

\section{Descriptive characteristics of participants (Table 1)}

A total of 291 (95\%) nurses completed the questionnaire. The mean age of the respondents was $34.6 \pm 7.4$ years. Only 11 (3.8\%) respondents had relevant clinical research training, while average duration of training varied from 1 to 5 days. Twenty-five nurses (8.6\%) were found to have experience in clinical research. Their responsibilities in these researches included collecting samples from clinical research participants such as blood, urine, tissue, etc. (18 nurses, $6.2 \%)$, monitoring the participants' vital signs (20 nurses, $6.9 \%)$, applying investigational material products such as medicines, medical devices, etc. (16 nurses, 5.5\%), monitoring level of the participants' pain (1 nurse, $0.3 \%$ ) and coordinating clinical research ( 1 nurse, $0.3 \%$ ) (For this question, the participants could mark more than one option).

\section{Findings of participants' knowledge of clinical research (Table 2)} Nineteen items, which evaluated knowledge level of each respondent regarding clinical researches, have been divided into three groups to have better understanding in the results.

- Group 1 -Items 1 to 7 (7 items): Definition of clinical research, ethical concept and regulations.

- Group 2 -Items 8 to 16 (9 items): Volunteering concept.

- Group 3 -Items 17 to 19 (3 items): Clinical research design. 


\begin{tabular}{|c|c|c|}
\hline Descriptive characteristics $(n=291)$ & $\mathbf{n}$ & $\%$ \\
\hline \multicolumn{3}{|l|}{ Age $^{+}$} \\
\hline$<35$ & 146 & 50.9 \\
\hline$\geq 35$ & 141 & 49.1 \\
\hline \multicolumn{3}{|l|}{ Gender } \\
\hline Man & 6 & 2.1 \\
\hline Woman & 285 & 97.9 \\
\hline \multicolumn{3}{|l|}{ Marital status } \\
\hline Married & 192 & 66.0 \\
\hline Single & 99 & 34.0 \\
\hline \multicolumn{3}{|l|}{ Area of work } \\
\hline Medical & 158 & 54.3 \\
\hline Surgical & 133 & 45.7 \\
\hline \multicolumn{3}{|l|}{ Educational background } \\
\hline Health vocational high school and associate degree license & 26 & 8.9 \\
\hline Bachelor's degree & 237 & 81.4 \\
\hline Master and $\mathrm{PhD}$ degree & 28 & 9.6 \\
\hline \multicolumn{3}{|l|}{ Nursing experience ${ }^{*}$} \\
\hline $0-9$ years & 133 & 46.0 \\
\hline $10-19$ years & 105 & 36.4 \\
\hline $20-33$ years & 51 & 17.6 \\
\hline \multicolumn{3}{|l|}{ Second language } \\
\hline Speak English & 250 & 85.9 \\
\hline Don't speak English & 41 & 14.1 \\
\hline \multicolumn{3}{|l|}{ Training in clinical research } \\
\hline Having training & 11 & 3.8 \\
\hline Not having training & 280 & 96.2 \\
\hline \multicolumn{3}{|l|}{ Experience in clinical research } \\
\hline Having relevant experience & 25 & 8.6 \\
\hline Not having relevant experience & 266 & 91.4 \\
\hline \multicolumn{3}{|c|}{ Having provided consultancy to patients about clinical research } \\
\hline Yes & 29 & 10.0 \\
\hline No & 262 & 90.0 \\
\hline
\end{tabular}

+4 nurses did not state their ages.

$¥ 2$ nurses did not state their experiences.

Out of the items in Group 1, the one that received the highest number of correct answers was "clinical researches cannot be started without ethics committee approval". More than $50.0 \%$ of the nurses had no idea about the Helsinki Declaration and Good Clinical Practice (GCP) information. The item giving the definition of a volunteer, was the most correctly answered question amongst all 19 items. On the other hand, the item about clinical research with vulnerable subjects was the least accurately answered statement in all three groups. The proportion of respondents who correctly answered the items in Group 3 did not exceed $37.8 \%$.

\section{Factors affecting participants' knowledge levels related to} clinical research

The mean of knowledge level of the respondents regarding clinical research was 10.1 \pm 4.1 (max: 19). Knowledge level was found to be significantly higher; 1 ) in the nurses who had had relevant clinical research training $(14.6 \pm 3.0)$ vs. who had not $(9.9 \pm 4.1)(p<0.001)$; 2) who had participated in prior clinical research $(12.5 \pm 4.4)$ vs. who had not $(9.9 \pm 4.0)(p=0.002)$ and 3$)$ who had provided prior consultancy related to clinical research $(12.2 \pm 4.5)$ vs. who had not $(9.9 \pm 4.0)(p=0.001)$.

Findings of participants' attitude towards clinical research (Table 3) The mean positive attitude score of the nurses regarding the clinical researches was found as $5.8 \pm 1.7$ (max: 8). Items indicating that clinical research is important for the progress of medical science $(92.8 \%)$ and that clinical research is useful for the population (89.0\%) received the highest positive responses, while the item describing that clinical research is reliable received the lowest positive response (45.4\%) in this group.

The level of attitudes towards clinical research were significantly higher in the nurses who had provided prior consultancy related to clinical research $(6.5 \pm 1.2)$ vs. who had not $(5.7 \pm 1.7)(t(289)=2.07, p<0.05)$.

There was a significantly positive correlation between the knowledge level and the attitude scores towards clinical research $(r=0.35, p<0.01)$. 
Table 2. Distribution of participants answers to 19 items for evaluating the knowledge level of the respondents regarding clinical research

\begin{tabular}{|c|c|c|c|c|c|c|}
\hline & \multicolumn{2}{|c|}{ Correct answer } & \multicolumn{2}{|c|}{ Incorrect answer } & \multicolumn{2}{|c|}{ No idea } \\
\hline & $\mathbf{n}$ & $\%$ & $\mathbf{n}$ & $\%$ & $\mathbf{n}$ & $\%$ \\
\hline \multicolumn{7}{|l|}{ Description of clinical research, ethical concepts and regulations $(n=291)$} \\
\hline $\begin{array}{l}\text { Item 1: Clinical research is a study of drug, biologic or device in human } \\
\text { subjects with the intent to discover potential beneficial effects and/or } \\
\text { determine its safety and efficacy. }\end{array}$ & 194 & 66.7 & 26 & 8.9 & 71 & 24.4 \\
\hline $\begin{array}{l}\text { Item2: Before a new medicine can be made available to the public, it must be } \\
\text { tested on humans. }\end{array}$ & 78 & 26.8 & 136 & 46.7 & 77 & 26.5 \\
\hline $\begin{array}{l}\text { Item3: Clinical research cannot be initiated without an ethics committee } \\
\text { approval. }\end{array}$ & 248 & 85.2 & 3 & 1 & 40 & 13.8 \\
\hline $\begin{array}{l}\text { Item 4: It is impossible to start a new clinical research without having an } \\
\text { approval from Turkish Medicines and Medical Devices Agency }\end{array}$ & 139 & 47.8 & 8 & 2.8 & 144 & 49.5 \\
\hline $\begin{array}{l}\text { Item 5: Clinical research should be conducted in accordance with the ethical } \\
\text { principles that have their origin in the Declaration of Helsinki, and that are } \\
\text { consistent with Good Clinical Practice (GCP) and the applicable regulatory } \\
\text { requirement (s). }\end{array}$ & 113 & 38.8 & 2 & 0.7 & 176 & 60.5 \\
\hline $\begin{array}{l}\text { Item 6: GCP is an international ethical and scientific quality standard for } \\
\text { designing, conducting, recording and reporting research that involve the } \\
\text { participation of human subjects. }\end{array}$ & 129 & 44.3 & 0 & 0 & 162 & 55.7 \\
\hline $\begin{array}{l}\text { Item 7: Compliance with this GCP provides public assurance that the rights, } \\
\text { safety and well-being of research subjects are protected. }\end{array}$ & 139 & 47.8 & 2 & 0.7 & 150 & 51.5 \\
\hline \multicolumn{7}{|l|}{ Voluntary concept in clinical research $(n=291)$} \\
\hline $\begin{array}{l}\text { Item 8: A volunteer is defined as a patient or healthy person who participate } \\
\text { in a clinical research and provide a written informed consent obtained from } \\
\text { either the participant or a legally authorized representative of the participant. }\end{array}$ & 265 & 91.1 & 3 & 1 & 23 & 7.9 \\
\hline $\begin{array}{l}\text { Item 9: The informed consent form (ICF) is a document which provides } \\
\text { detailed and comprehensible information about a clinical research to the } \\
\text { voluntaries who are considering to participate in clinical research and verifies } \\
\text { the written request }\end{array}$ & 225 & 77.3 & 0 & 0 & 66 & 22.7 \\
\hline $\begin{array}{l}\text { Item 10: The volunteer must sign the ICF before participating in a clinical } \\
\text { research. }\end{array}$ & 228 & 78.4 & 2 & 0.7 & 61 & 20.9 \\
\hline Item 11: Participants safety in clinical research is a high priority. & 230 & 79.0 & 3 & 1 & 58 & 19.9 \\
\hline $\begin{array}{l}\text { Item 12: Clinical research with children, pregnant and lactating, well-off } \\
\text { patients and restrictions is strictly prohibited under national legislation. }\end{array}$ & 14 & 4.8 & 173 & 59.5 & 104 & 35.7 \\
\hline $\begin{array}{l}\text { Item 13: In clinical research, participants' personal and medicinal information } \\
\text { is kept confidential. }\end{array}$ & 242 & 83.2 & 4 & 1.4 & 45 & 15.5 \\
\hline $\begin{array}{l}\text { Item 14: Volunteers cannot be proposed of high payments to encourage their } \\
\text { participation in clinical research. }\end{array}$ & 126 & 43.3 & 9 & 3.1 & 156 & 53.6 \\
\hline $\begin{array}{l}\text { Item 15: A participant can leave a clinical research at any time without giving } \\
\text { a reason. }\end{array}$ & 148 & 50.9 & 19 & 6.5 & 124 & 42.6 \\
\hline $\begin{array}{l}\text { Item 16: The treatment costs of the adverse effects that occur during the } \\
\text { clinical research are covered by the sponsor. }\end{array}$ & 148 & 50.9 & 11 & 3.8 & 132 & 45.4 \\
\hline \multicolumn{7}{|l|}{ Design of clinical research $(n=291)$} \\
\hline Item 17: It is possible to use placebo in clinical research. & 110 & 37.8 & 25 & 8.6 & 156 & 53.6 \\
\hline $\begin{array}{l}\text { Item 18: Blindness (single-blind, double-blind) is used in clinical research to } \\
\text { avoid errors arising from partiality and bias. }\end{array}$ & 86 & 29.6 & 9 & 3.1 & 196 & 67.4 \\
\hline $\begin{array}{l}\text { Item 19: Randomization is used in clinical research to avoid errors arising } \\
\text { from partiality and bias. }\end{array}$ & 80 & 27.5 & 24 & 8.3 & 187 & 64.3 \\
\hline
\end{tabular}

Findings of participants' opinions about clinical research nursing The following opinions "clinical research should be considered as part of nursing education" and "clinical research nursing should be a separate profession" were responded positively by $85.2 \%$ and $75.6 \%$ of nurses, respectively. When the respondents were asked if they wanted to be involved in clinical research, 51.5\% answered "yes", while 48.5\% answered "no". Out of those who answered "no", $56.0 \%$ stated that the reason for their decision was the increase in workload.
When the participants were asked about the benefits of being involved in clinical research, the highest rate was acquired for "contributing to nurses' specialization" (76.3\%) and the lowest rate for "increasing patient safety" (47.1\%).

Effects of knowledge levels and attitudes of the participants on their opinions towards clinical research nursing were shown in Table 4. 


\begin{tabular}{|c|c|c|c|c|c|c|}
\hline \multirow[t]{2}{*}{$\begin{array}{l}\text { Attitudes toward clinical research } \\
(n=291)\end{array}$} & \multicolumn{2}{|c|}{ I agree } & \multicolumn{2}{|c|}{ I do not agree } & \multicolumn{2}{|c|}{$\begin{array}{l}\text { Neither agree or } \\
\text { disagree }\end{array}$} \\
\hline & $n$ & $\%$ & $\mathbf{n}$ & $\%$ & $\mathbf{n}$ & $\%$ \\
\hline Item 1: Clinical research improves the quality of patient care. & $239^{+}$ & $82.1^{+}$ & 11 & 3.8 & 41 & 14.1 \\
\hline Item 2: Clinical research is beneficial for the society. & $259^{+}$ & $89.0^{+}$ & 8 & 2.8 & 24 & 8.3 \\
\hline Item 3: Clinical research is important for advancing medicine. & $270^{+}$ & $92.8^{+}$ & 6 & 2.06 & 15 & 5.2 \\
\hline Item 6: Standard treatments are always more trustworthy than new investigational drug. & 42 & 14.4 & $149^{+}$ & $51.2^{+}$ & 100 & 34.4 \\
\hline Item 7: Patients can refuse to take a part in clinical research without affecting their treatment. & $187^{\dagger}$ & $64.3^{+}$ & 27 & 9.28 & 77 & 26.5 \\
\hline Item 8: Nurses are supposed to have more knowledge in clinical research. & $256^{+}$ & $88.0^{+}$ & 12 & 4.1 & 23 & 7.9 \\
\hline
\end{tabular}

Table 4. Effects of knowledge levels and attitudes of the participants on their opinions towards clinical research nursing

Means of knowledge \pm SD

$\mathbf{p}$

Means of attitudes \pm SD

p

Clinical research nursing should be considered as a profession.

Yes

No and No Idea
$10.7 \pm 3.9$

$8.2 \pm 3.9$

$10.3 \pm 4.1$

$8.9 \pm 3.9$ $p<0.001$

0.03

3

$11.0 \pm 4.2$

$9.2 \pm 3.9$
$6.1 \pm 1.5$
$4.9 \pm 1.9$

$p<0.001$

$6.1 \pm 1.5$

$4.6 \pm 2.2$

$6.4 \pm 1.3$

$5.3 \pm 1.9$ $p<0.001$

$p<0.001$

No and No idea

$p<0.001$

\section{DISCUSSION}

We evaluated the staff nurses' knowledge, attitudes and opinions about clinical research and clinical research nursing working at Dokuz Eylul University Hospital. Although this is one of the important centers in our country conducting global clinical research, we found that only $8.6 \%$ of the respondents had participated in prior clinical research. Some possible explanations for the low level of participation could be related to knowledge and attitudes of staff nurses about clinical research. There are many studies in the literature reporting that nurses' lack of knowledge and experience in clinical researches, time issues and lack of support for their participation in clinical researches are major obstacles for nurses' involvement and participation in clinical researches $(6,13,19)$.

In our study, we found that very little number of nurses (3.8\%) had undergone clinical research training, most of which were unstructured. The mean of nurses' knowledge level regarding clinical research was found 10.1 \pm 4.1 (max: 19) and this result is congruent with the literature indicating that the nurses have average or limited knowledge of clinical research $(13,18,20)$. Our finding as well as literature data show that there is a need for a structured training programme for the nurses who will participate in clinical researches $(5,6,13,19,20)$. The knowledge level of nurses was related to whether or not they had had prior clinical research training, had participated in clinical research, and had provided prior consultancy related to clinical research.
CRNs have an important role in supporting and monitoring the integrity of studies and ensuring the safety of volunteers and protecting their rights and interests. To perform this task, they should be knowledgeable about GCP, Declaration of Helsinki, and legislations on clinical researches $(3,18)$. However, our findings showed that nurses' awareness about these regulations was limited. Despite this lack of general awareness, their knowledge on volunteering issues, such as definition of volunteering and informed consent, and confidentiality of volunteers was satisfactory. Similarly, nurses have been found to be quite knowledgeable on volunteering issues in the literature (18). This might probably be due to the fact that such issues are already among the responsibilities of nurses in their routine clinical practice. On the other hand, knowledge of nurses was especially limited in clinical research on vulnerable volunteers, which was due to their unawareness of related legislations. The nurses also had lack of basic knowledge about the design of clinical research. This may lead to staff nurses to experience difficulties in communication and co-operation with the clinical research team (13), as stated in the literature.

Nurses reported that when patients request information about the benefits and risks of clinical research, they feel uncomfortable providing this information to the patients due to their lack of sufficient experience, and knowledge in clinical researches (13). It is also stated that as their knowledge level increases, they are able to provide required information to the patients much more confidently (20). It has been shown that the number of 
volunteers participating in clinical research increased when they were properly informed about the risks and benefits of the research (12). It is evident that well trained nurses help increase the number of volunteers by properly informing them. Therefore, the institutions willing to perform more clinical research should encourage the nurses to undergo clinical research training.

In our study; the mean of the answers given by the nurses to evaluate their attitudes towards clinical research was found to be $5.8 \pm 1.7$ out of 8 points. The vast majority of the nurses stated that clinical research is useful for the society and plays a vital role in increasing the quality of patient care and the progress of the medical science. This result suggests that nurses show a positive attitude towards clinical research. It is an important finding since this attitude may also affect the collaboration with the clinical research team, the conduct of the research protocol, the quality of the voluntary care and safety, the reliability of the data, the number of volunteers, and hence the success of clinical research $(3,6,12,17,21-23)$.

Another important finding in our study is that only fewer than half of the nurses agreed on the following statement: "Clinical researches are reliable studies". This was used to evaluate their attitudes towards the clinical research. This may be due to their lack of knowledge regarding to the legislations about the ethical aspects of clinical research. Positive attitudes of nurses towards clinical research can be expected to be important in increasing the productivity of clinical research training, since attitudes have an important role in the realization of training objectives.

Factors such as socio-cultural factors, gender and age, and area of work also play an important role in shaping attitudes (24). In our study, we found that the age, area of work, duration of study or nursing education did not have a significant effect on the attitude scores of the nurses. However, as their knowledge on clinical research increased, there was an increase in the positive attitude, although not statistically significant. The lack of statistical significance was probably due to the limited number of nurses who had prior training or clinical research experience. In fact, it has been shown that there is a positive relationship between education and attitudes towards clinical research (14). The attitude scores of the nurses who had provided prior consultancy about clinical research were significantly higher than the other nurses, and this can be regarded as an expected finding because their knowledge level is also relatively higher.

Vast majority of the nurses agreed on the following statement: "Clinical research should be considered as part of nursing education". Moreover, nurses with high scores of knowledge and attitude were relatively more willing to agree on this opinion in comparison with the rest. This result is in parallel with studies in the literature that demonstrate the willingness of nurses to receive training in clinical research $(18,20,25-26)$.

As nurses continue to specialize in a variety of fields, job descriptions for new areas of expertise are being made (27). Clinical research nursing is one of the areas of expertise (12). In order to increase the success of clinical research, it is of paramount importance to recognize clinical research nursing as a specialty. Most of the respondents in our study agreed with this statement.

In our study, it was determined that more than half of the nurses wanted to take part in clinical research, and the nurses with higher knowledge and attitude scores gave more "yes" answers to this question than the nurses with lower scores. Considering the need for educated workforce in clinical research in particular, it is a noteworthy as well as an encouraging result. Among the reasons for not being willing to take part in clinical research was the possible increase in their workload, and also their lack of knowledge in clinical research. This result is congruent with the studies in the literature that emphasize the crucial importance of education and training in motivating and encouraging healthcare professionals to take part in clinical research $(6,19,25,28,29)$.

\section{Study Limitations}

Systematic sampling was not possible and only nurses who volunteered to participate in the study could be included.

\section{CONCLUSION}

We found that only few of the nurses had prior experience in clinical research, most of the nurses did not have any relevant training in clinical research, and that the training they received was not standard. Nurses' level of knowledge depended on their relevant training, prior participation in clinical research, and prior consultancy provided to patients. We also found that the majority of the nurses were aware of the concepts of volunteering and safety of volunteers in clinical research but had limited knowledge of the related regulations and the design of research. Despite the small number of nurses working in clinical research, it was observed that the majority of the nurses showed a positive attitude towards clinical research. Additionally, it was also observed that the knowledge of clinical research plays a role in nurses' positive attitudes towards clinical research. Moreover, both knowledge and attitude of the nurses had a significant impact on nurses' opinions regarding specialization, education, and participation in clinical research.

Ethics Committee Approval: This study was approved by Dokuz Eylul University Ethics Committee for Non-Interventional Research, and was conducted in accordance with the Declaration of Helsinki.

Informed Consent: Written informed consent was obtained from patient who participated in this case

Peer-review: Externally peer-reviewed.

Author Contributions: Concept - AG, HBA, RU, MAA; Design - AG, HBA, RU, MAA Supervision - AG, RU, MAA; Resource - ; Materials - HBA; Data Collection and/ or Processing - HBA; Analysis and/or Interpretation - AG, HBA, RU, MAA; Literature Search - AG, HBA; Writing - AG, HBA; Critical Reviews - RU, MAA

Conflict of Interest: The authors declare that there are no conflicts of interest.

Financial Disclosure: This study has received no financial support

Acknowledgements: The abstract of the manuscript was presented as a poster in European Congress of Pharmacology (EPHAR) 2016, İstanbul, Turkey P 195, p.481. 


\section{REFERENCES}

1. Downing A, Morris EJ, Corrigan N, et al. High hospital research participation and improved colorectal cancer survival outcomes: a population-based study. Gut 2017;66:89-96. [CrossRef]

2. Gallin JI, Ognibene FP. Principles and Practice of Clinical Research, 3rd ed. London: Elsevier/Academic Press; 2012.

3. Grady C, Edgerly M. Science, technology, and innovation: Nursing responsibilities in clinical research. Nurs Clin North Am 2009;44:471481. [CrossRef]

4. Green L. Explaining the role of the nurse in clinical trials. Nurs Stand 2011;25:35-39. [CrossRef]

5. Dhodi DK, Thakkar KB, Billa G, Khobragade AA, Sinha SR, Patel SB. Knowledge, attitude \& practices of medical students and teachers towards clinical research in a tertiary care hospital in Mumbai -cross sectional survey. J Contemp Med Edu 2013;1:238-244. [CrossRef]

6. Roll L, Stegenga K, Hendricks-Ferguson V, et al. Engaging nurses in research for a randomized clinical trial of a behavioral health intervention. Nurs Res Pract 2013;2013:183984. [CrossRef]

7. Bevans $M$, Hastings $C$, Wehrlen $L$, et al. Defining clinical research nursing practice: results of a role delineation study. Clin Transl Sci 2011;4:421-427. [CrossRef]

8. Castro K, Bevans M, Miller-Davis C, et al. Validating the clinical research nursing domain of practice. Oncol Nurs Forum 2011;38:E72E80. [CrossRef]

9. Gibbs $\mathrm{CL}$, Lowton $\mathrm{K}$. The role of the clinical research nurse. Nurs Stand 2012;26:37-40. [CrossRef]

10. Hastings $C E$, Fisher $C A, M c C a b e ~ M A$, et al. Clinical research nursing: a critical resource in the national research enterprise. Nurs Outlook 2012;60:149-156. [CrossRef]

11. Kenkre JE, Chatfield D. Study site co-ordinator/Clinical research nurse; A career for nurses in the pharmaceutical industry? CRfocus 2004;15:5-9.

12. Spilsbury K, Petherick E, Cullum N, Nelson A, Nixon J, Mason S. The role and potential contribution of clinical research nurses to clinical trials. J Clin Nurs 2008;17:549-557. [CrossRef]

13. Matsumoto K, Nagamura F, Ogami Y, Yamashita N, Kamibeppu K. Difficulties of nursing staff involved in phase 1 oncology trials in Japan. Cancer Nurs 2011;4:369-375. [CrossRef]

14. Zhang J, Zhang H, Yu C, Li J, Jiang Y. The attitudes of oncology physicians and nurses toward phase I, II, and III cancer clinical trials. Contemp Clin Trials 2011;32:649-653. [CrossRef]

15. Flocke SA, Antognoli E, Daly BJ, et al. The Role of Oncology Nurses in Discussing Clinical Trials. Oncol Nurs Forum 2017;44:547-552. [CrossRef]
16. Bulut Aksoy H, Gelal A. Role of the Clinical Research Nurse: Review. Turkiye Klinikleri J Nurs Sci 2016;8:271-276. [CrossRef]

17. Burnett CB, Koczwara B, Pixley L, Blumenson LE, Hwang YT, Meropol NJ. Nurses' attitudes toward clinical trials at a comprehensive cancer center. Oncol Nurs Forum 2001;28:1187-1192.

18. Yanagawa $\mathrm{H}$, Takai S, Yoshimaru M, Miyamoto T, Katashima R, Kida $\mathrm{K}$ Nurse awareness of clinical research: a survey in a Japanese University Hospital. BMC Med Res Methodol 2014;14:85. [CrossRef]

19. MacLean S, Désy P, Juarez A, Perhats C, Gacki-Smith J. Research education needs of pediatric emergency nurses. J Emerg Nurs 2006;32:17-22. [CrossRef]

20. Ulrich CM, Zhou Q, Ratcliffe SJ, Ye L, Grady C, Watkins-Bruner D. Nurse practitioners' attitudes about cancer clinical trials and willingness to recommend research participation. Contemp Clin Trials 2012;33:76-84. [CrossRef]

21. Michaels M, D'Agostino TA, Blakeney $N$, et al. Impact of primary care provider knowledge, attitudes, and beliefs about cancer clinical trials: implications for referral, education and advocacy. J Cancer Educ 2015;30:152-157. [CrossRef]

22. Rice J, Cheak TL. The role of nursing in hospital-based clinical research. The Am J Nurs 2000;100:24E-24G.

23. Sadler GR, Lantz JM, Fullerton JT, Dault Y. Nurses' unique roles in randomized clinical trials. J Prof Nurs 1999;15:106-115.

24. Poat $A$, McElligott $M$, Fleming V. How midwives' attitudes can affect the research process. BrJ Midwifery 2013;11:396-400. [CrossRef]

25. Caldwell B, Coltart K, Hutchison C, et al. Research awareness, attitudes and barriers among clinical staff in a regional cancer centre. Part 1: a quantitative analysis. Eur J Cancer Care (Engl) 2017;26. [CrossRef]

26. Johnson C, Lizama C, Harrison M, Bayly E, Bowyer J, Haddow L. Cancer health professionals need funding, time, research knowledge and skills to be involved in health services research. J Cancer Educ 2014;29:389-394. [CrossRef]

27. Stephens-Lloyd A. The extended role of the clinical research nurse: Building an evidence base for practice. Res Nurs Health 2004;9(1):1827. [CrossRef]

28. McSherry R, Artley A, Holloran J. Research awareness: An important factor for evidence-based practice? Worldviews Evid Based Nurs 2006;3:103-115. [CrossRef]

29. Ooi CC, Lee SHE, Soh BP. A survey on the research awareness and readiness among radiographers in Singapore General Hospital (SGH). Radiography 2012;18:264-269. [CrossRef] 